\title{
INTRODUCING DESIGN HEURISTICS FOR FURNITURE DESIGN IN A FURNITURE DESIGN COURSE
}

\author{
Supradip DAS and Amarendra Kumar DAS \\ Department of Design, Indian Institute of Technology Guwahati
}

\begin{abstract}
Concept generation in the early design phase is a deciding factor in any design innovation process. And the magnitude of the concepts generated in the initial design phase is the measurable criteria for success. Experienced designers travel through their world of objects, observations, encoded information, and collection of prior experiences to externalize multiple concepts through different tools. However, novice designers experience difficulties exploring the problem space and fixate on the concepts with the initial features. Researchers suggested many formal tools or methods for concept generation in the early phases of design to overcome these issues. Many of these are difficult to use by novice designers and many of these are very generic to product design. This paper discusses a concept generation tool for novice furniture designers 'Design Heuristics for Furniture Design' (DHfFD) with special emphasis on the chair, which has been developed from the study and analysis of award-winning furniture (chair) and published compendium of well-known, successful designs. To understand how the DHfFD cards are perceived by novice designers in use, the tool was introduced in a furniture design course, and a qualitative study was performed with novice design students at the Department of Design, IIT Guwahati. It is observed from the study that the DHfFD tool helps to generate diverse concepts within a short duration of time. This research integrates design tools and cognition in design; accordingly, it recommends using 'Design Heuristics for Furniture Design' (DHfFD) in a furniture design course.
\end{abstract}

\section{Keywords: Design Heuristics for Furniture Design, tool for concept generation, furniture design}

\section{INTRODUCTION}

Research expounds that frequent unwanted design innovation project dissolution occurs at two points [1]: a) after concept generation and selection process, b) after the market introduction. Therefore, concept generation in the divergent phase of the creative problem-solving process has a decisive influence on the success of any innovation [2] [3], and statistically, the success of the concept generation is significantly co-related to the quantity of the concepts generated [4]. Although researchers proposed several formal methods [5], existing methods have the following issues: 1) unstructured or intuitive [6], 2) difficulty in acquisition [7], 3) difficulty in assessing the concepts [8], 4) lack of validation [9]. An empirical investigation shows that analogical problem solving [10], which is assisted by the solutions from past problems, is an effective tool for scaffolding in design education [11]. Thus, heuristics is a widely accepted tool for concept generation [12], as these are developed based on the principle of analogical problem-solving. The above factor motivated many researchers to develop heuristics for concept generation. Existing heuristics are industrial and product design-oriented and not much support for furniture designers specifically. This research discusses the impact of the tool DHfFD on novice designers.

\section{AIM AND OBJECTIVE}

Previous research related to the effectiveness of the different heuristics observed successful concept generation with heuristics. As the developed tool is from a completely different domain, it is thus necessary to confirm the impact and perception of the developed tool in practice. The research aims to investigate the tool's performance during concept generation and to understand how the tool is perceived. To achieve the desired aim, the tool was introduced in a furniture design course and a qualitative study was performed with novice design students at the Department of Design, IIT Guwahati, India. 


\section{HEURISTICS IN DESIGN}

The heuristic is described in the literature as a rule of thumb, cognitive short-cut, engineering strategy, cognitive problem-solving tool, etc. A heuristic is defined as "a context-dependent directive, based on intuition, tacit knowledge, or experiential understanding, that provides design process direction to increase the likelihood of reaching a satisfactory but not necessarily optimal solution" [13]. Notwithstanding the limitation, heuristics are well accepted, as they help in divergent thinking. The existing heuristic approaches in design research are SCAMPER [14], TRIZ [15], SYNECTICS [16], 77 Design heuristics [17], Design heuristics for additive manufacturing [18], Transformation design theory [19], Portability design heuristics [20], Design heuristics set for assistive product design [21], Design aesthetic heuristics [22], Design heuristics for innovative packaging [23], Heuristics in ergonomic design of portable control devices for elderly [24] and new design heuristics for digital era [25] etc.

\section{DESIGN HEURISTICS FOR FURNITURE DESIGN}

The design heuristics above can be categorized into two [21]: 1) Comprehensive Design Heuristics (CDHs), which do not have any pre-specified purposes and may be useful across all design domains; example: TRIZ, 77 Design Heuristics, 2) Design heuristics for X, which do have pre-specified purposes and are useful in domain-specific problems; example: Design heuristics for assistive product design, Design heuristics for additive manufacturing. As there are no heuristics available for furniture design, in a previous work a collection of 66 heuristics were developed [26], which fall under the category of Design heuristics for $\mathrm{X}$. The research was focused on the second category and the developed tool is called Design Heuristics for Furniture Design (DHfFD), which emphasizes chair design. The collection of heuristics was developed based on extensive study and analysis of existing furniture (chair) design analogy from Design award repertoire, published compendium, catalogue of leading furniture manufactures, and online design magazines. The existing pieces of furniture were grouped as suggested in the K-J method based on the form \& structure and special features. Analysis and heuristic extraction of each group has been done, as indicated in literature [27].

\section{EXPERIMENTAL APPROACH}

\subsection{Research Question}

This research seeks to understand the effect of DHfFD on creative idea generation by novice designers in a furniture design course and sought to answer the following research questions:

1) Does using DHfFD result in more innovative furniture designs?

2) How do novice designers perceive DHfFD in use?

\subsection{Participants}

A total of 28 novice designers participated in the study from undergraduate and postgraduate design courses with no prior experience in furniture design and no idea about DHfFD.

\subsection{Method}

In this study, a longitudinal research approach was adopted. The same group of novice designers generated ideas before and after the introduction of the tool Design heuristics for furniture design. The main reason behind adopting a longitudinal research approach was to confirm the treatment effect on participants and register changes in individual participants.

The experiment was conducted in four phases, as illustrated in Figure 1. The four phases are the control treatment phase, the experimental treatment phase, the survey phase, and the evaluation phase. The control treatment phase began by asking participants to generate solutions without any tool being given. Participants got 30 minutes to complete the task. A gap of 30 days was there between phase I and phase II to avoid the pre-treatment assessment's effect on post-treatment. At the beginning of the experimental treatment phase, the DHfFD tool was introduced through a lecture. During the experimental treatment phase, students were asked to generate concepts within 30 minutes using DHfFD cards. In both phases I and II, the students were given an open-ended challenge and asked to produce as many ideas as possible in 30 minutes.

Brief: Design as many as possible indoor chairs for urban housing. There is no constraint of cost, material, and process. 


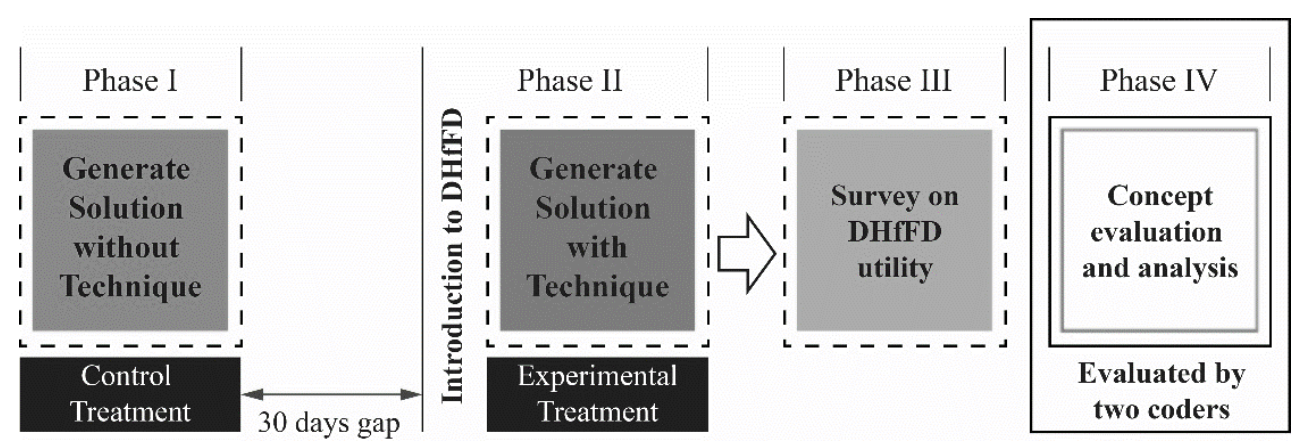

Figure 1. Experimental execution diagram

In this study at the experimental treatment phase, a total of 12 DHfFD cards were introduced. The cards were selected randomly from a set of 66 heuristic cards set. On a two-sided 80 x $100 \mathrm{~mm}$ card, each heuristic was presented. Design heuristics cards for furniture design have the following content in each card as shown in Figure 2: design heuristic number, design heuristic name, an abstract representation of the design heuristic through illustration, design heuristic description, instructions for designers, real examples associated with the heuristics.

FRONT

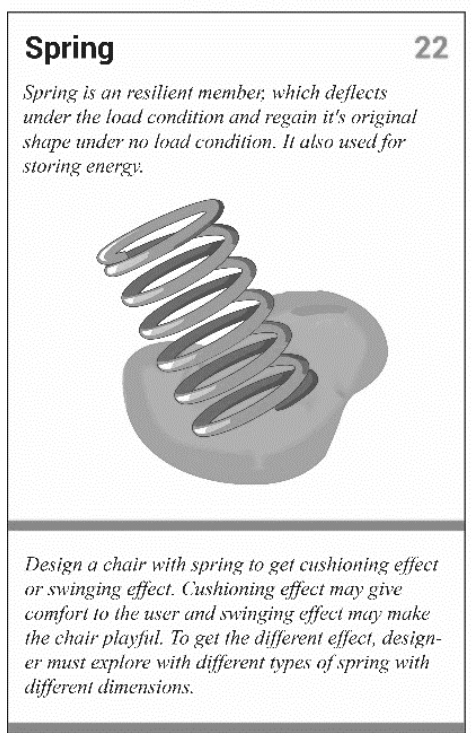

BACK

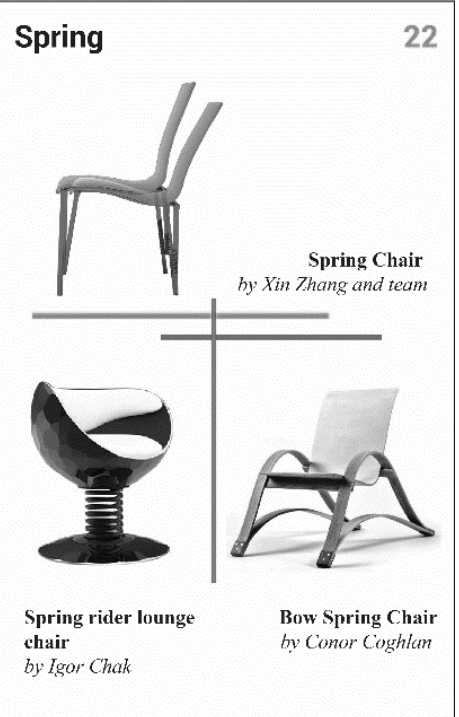

Figure 2. DHfFD card

Cards were not provided one at a time, in a standard order, as it may restrict the flexible use of the tool in more than one manner, and it may also create a problem for future acquisition of the tool. They were given the liberty to use the cards the way they wanted. The given card list is shown in Table 1.

Table 1. Set of 12 Heuristics Provided in Study

\begin{tabular}{|l|l|l|}
\hline Cantilever & Wave surface & Spring \\
\hline Wiggle & Tensegrity & Coil \\
\hline Extension & Playful & Tensile surface structure \\
\hline Collapsible & Comet structure & Science \& Technology \\
\hline
\end{tabular}

In phase III, the participants were asked to respond to a series of questions on a Likert scale from 1 to 5. One-to-one discussions with students were also arranged to gather suggestions and understand the reason behind their perspective towards the tool. The students were asked the following questions in Table 2 .

Table 2. Questions submitted to the students

\begin{tabular}{|l|l|l|}
\hline Q\# & Text of Questions & Scale \\
\hline Q1 & $\begin{array}{l}\text { How effective was the tool in helping you to generate more concepts } \\
\text { of a chair? }\end{array}$ & $\begin{array}{l}(1=\text { Not effective, 5 = Very } \\
\text { effective })\end{array}$ \\
\hline
\end{tabular}




\begin{tabular}{|c|c|c|}
\hline Q2 & $\begin{array}{l}\text { How would you rate the appropriateness of the textual content of the } \\
\text { tool? }\end{array}$ & $(1=$ Very poor, $5=$ Very good $)$ \\
\hline Q3 & $\begin{array}{l}\text { How would you rate the appropriateness of the visual content of the } \\
\text { tool? }\end{array}$ & $(1=$ Very poor, $5=$ Very good $)$ \\
\hline Q4 & $\begin{array}{l}\text { How do you find the DHfFD for creative concept generation for chair } \\
\text { design? }\end{array}$ & $\begin{array}{l}(1=\text { Not effective, } 5=\text { Very } \\
\text { effective })\end{array}$ \\
\hline Q5 & $\begin{array}{l}\text { Was there a need for an explanation of any basic's concepts during } \\
\text { the application of the new tool? }\end{array}$ & $\begin{array}{l}(1=\text { Quite always, } 5=\text { Not at } \\
\text { all })\end{array}$ \\
\hline Q6 & $\begin{array}{l}\text { Was the tool useful to understand the types of form and structure of } \\
\text { chairs? }\end{array}$ & $\begin{array}{l}(1=\text { Not effective, } 5=\text { Very } \\
\text { effective })\end{array}$ \\
\hline
\end{tabular}

In phase IV, three coders were trained, and they evaluated the concepts generated in phase I and phase II based on the quantity, quality, novelty, and variety of ideas [28]. The coders also investigated the evidence of the use of DHfFD for the corresponding concepts generated by the participants in phase II. Coders were from the background of accessory design, applied arts, and architecture.

\section{RESULTS \& DISCUSSIONS}

\subsection{Major Findings from Phase I}

In phase I, 28 participants generated 140 concepts within a range of 3 to 12 . The concepts generated at phase I without any technique/tool have the following issues: 1) indistinguishable concepts presented, 2) existing ideas presented with minor modification, and 3) impractical concepts presented. Some of the examples are shown in Figure 3. Students in the sophomore years lack understanding of the form and structure of furniture (chair), which might be the primary reason behind the indistinguishable concepts. Impractical concepts resulted from a lack of experience and exposure of the participants. The scenario necessitates domain-specific support to scaffold novice designers for creative concept generation. Nevertheless, this phenomenon is not valid for all participants.

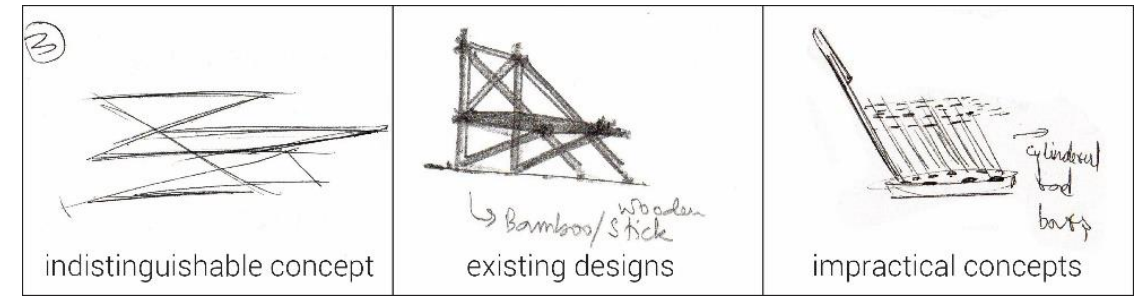

Figure 3. Concepts sketches from phase I

\subsection{Major Findings from Phase II}

In phase II, 28 participants generated 294 concepts within a range of 4 to 20 . The concepts at phase II are substantially improved in comparison to the concepts at phase I. Concepts with high novelty scores were observed when few participants combined more than one DHfFD card. Some examples of concepts with evident DHfFD heuristics are shown in Figure 4.

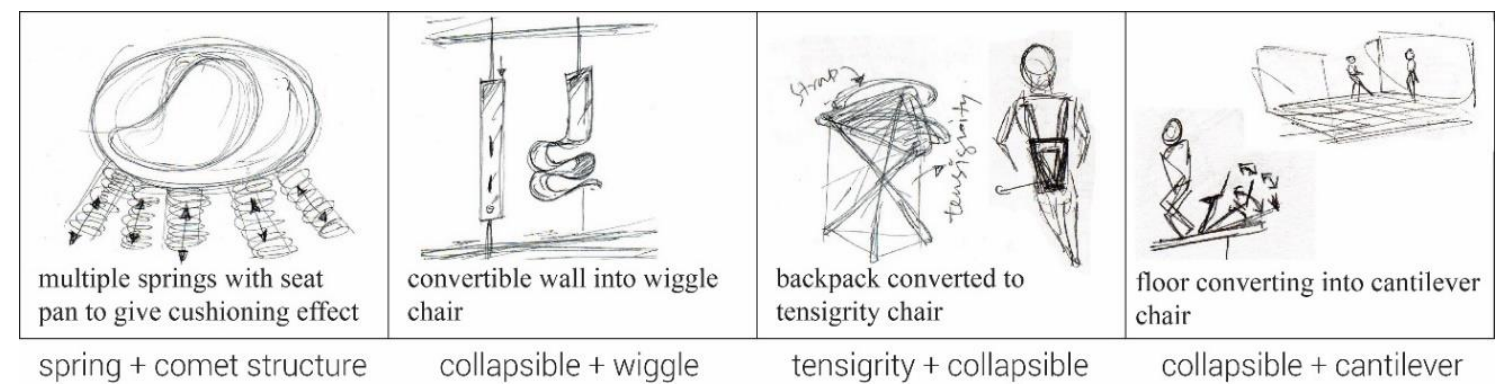

Figure 4. Example concepts with evident combined DHfFD heuristics from phase II

The presence of heuristics is observed in maximum concepts. It is important to say, maximum concepts are novel and practically possible with minor modification. 


\subsection{Major Findings from Phase III}

The coders compared the concepts generated in earlier phases and established the correlation between the number of concepts generated and the use of DHfFD cards. It is evident from the results and responses that the tool is helpful in creative concept generation and overall, the perspective of the students towards the DHfFD tool is positive, which reflects on the histograms of responses to the questions asked at phase III. The responses are visually summarized in Figure 5.

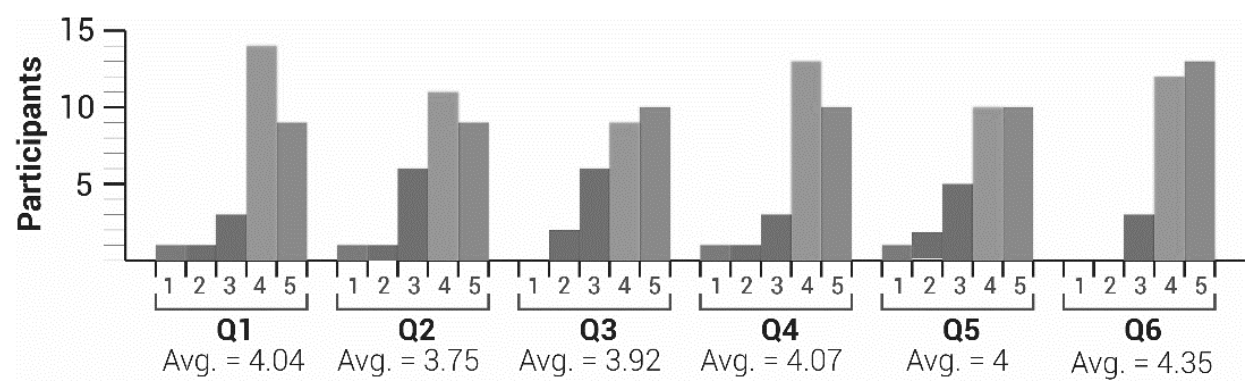

Figure 5. Responses of the participants

Along with the positive responses to the tool, a few invaluable pieces of feedback were registered at phase III during the discussion with the participants regarding the improvement of the tool. The following are the significant points that emerged from the conversation:

1. Transformational principles: Novice designers lack knowledge of transformational principles of the basic form and suggested the inclusion of cards with content related to transformational principles.

2. Tool for a tool: It is more important to refine concepts than the generation of concepts. If support is provided to make a prototype for the feasibility study, it would be helpful for beginning designers.

3. Separation of citation of furniture: Existing designs are influential and divert novice designers' minds while using the card and suggestions received to separate the instruction card and citation cards.

\section{RECOMMENDATION}

The study on introducing Design Heuristics for Furniture Design (DHfFD) to novice designers shows that the tool helps to generate diverse and novel concepts. This research integrates design tools and cognition in design; accordingly, it recommends using DHfFD in a furniture design course.

\section{CONCLUSIONS}

This paper discusses the impact of the recently developed tool Design Heuristics for Furniture Design (DHfFD) on novice designers while introducing it in an elective course setting. Critical observations at the control treatment phase point out novice designers' issues and necessitate domain-specific scaffolding. In conjunction with a controlled study, the tool was introduced in a course and the research indicates the tool stimulates novel and diverse concept generation. Questions and associated Likert-scale responses indicate a positive perception of the first introduction of the tool. Significant points that emerged from a conversation with the students are also the paper's key contribution. The pedagogical approach, teaching with DHfFD would help furniture design education, as there is no support available for concept generation specific to furniture design. The research mitigates the challenges of novice designers in innovative concept generation and contributes to design education. Despite the limited sample size, the findings may be applicable to similar circumstances.

\section{REFERENCES}

[1] Huber D., Kaufmann H., and Steinmann M. Bridging the Innovation Gap, 2014 (Springer International Publishing).

[2] Perttula M. and Sipilä P. The idea exposure paradigm in design idea generation. Journal of Engineering Design, 2007, 18(1), 93-102.

[3] Liu Y. C., Bligh, T. and Chakrabarti A.: Towards an "ideal" approach for concept generation. Design Studies, 2003, 24(4), 341-355. 
[4] Yang M. C. Concept generation and sketching: correlations with positive design outcome. In Proceedings of the ASME Design Engineering Technical \& Computers in Engineering Conferences, New York, 2003.

[5] Smith G. F. Idea-Generation Techniques: A Formulary of Active Ingredients. Journal of Creative Behaviour, 1998, 32(2), 107-134.

[6] Gero J. S., Hao J. and Christopher B. W. Design cognition differences when using unstructured, partially structured, and structured concept generation creativity techniques. International Journal of Design Creativity and Innovation, 2013, 1(4),196-214.

[7] Ilevbare I. M., Probert D., and Phaal R. A review of TRIZ, and its benefits and challenges in practice. Technovation, 2013, 33(2-3), 30-37.

[8] Al-Samarraie H. and Hurmuzan S. A review of brainstorming techniques in higher education. Thinking Skills and Creativity, 2018, 27, 78-91.

[9] Kotys-Schwartz D. A., Daly S. R., Yilmaz S., Knight D. and Polmear M. Evaluating the implementation of design heuristic cards in an industry-sponsored capstone design course. In ASEE Annual Conference \& Exposition, Indianapolis, Indiana, June 2014, pp. 24.544 .1 24.544.16.

[10] Bardasz T. and Zeid I. Applying analogical problem solving to mechanical design. ComputerAided Design, 1991, 23(3), 202-212.

[11] Daugherty J. and Mentzer N. Analogical reasoning in the engineering design process and technology education applications. Journal of Technology Education, 2008, 19(2), 7-21.

[12] Tessari R. K. and De Carvalho M. A. Compilation of heuristics for inventive problemsolving. Procedia Engineering, 2013, 131, pp 50-70.

[13] Fu K. K., Yang M. C., and Wood K. L. Design principles: Literature review, analysis, and future directions. Journal of Mechanical Design, 2016, 138(10):101103.

[14] Eberle B. Scamper on Games for Imagination Development, 1996 (Prufrock Press Inc).

[15] Altshuller G. 40 principles: TRIZ keys to innovation, 1996 (Technical Innovation Center).

[16] Roukes N. Design Synectics: Stimulating Creativity in Design, 1988 (Davis Publications).

[17] Yilmaz S., Daly S. R., Seifert C. M., and Gonzalez R. Evidence-based design heuristics for an idea generation. Design Studies, 2016, 46, 95-124.

[18] Blösch-Paidosh A. and Shea K. Design heuristics for additive manufacturing. In Proceedings of the 21st International Conference on Engineering Design, Vol 5: Design for X, Design to X, Vancouver, Canada, 2017, pp.91-100.

[19] Weaver J., Wood K., Crawford R., and Jensen D. Transformation design theory: A metaanalogical framework. Journal of Computing and Information Science in Engineering, 2010, 10(3):031012.

[20] Hwang D. and Park W. Development of portability design heuristics. In Proceedings of the International Conference on Engineering Design, ICED, Vol 5: Design for X, Design to X, Milan, Italy, July 2015, pp.81-90.

[21] Hwang D. and Park W. Design heuristics set for X: A design aid for assistive product concept generation. Design Studies, 2018, 58, 89-126.

[22] Cadavid A., Ruiz-Córdoba S. and Maya J. Extracting Design Aesthetic Heuristics from Scientific Literature. In Proceedings of DRS 2016, Brighton, UK, June 2016, pp. 179-202.

[23] Fuente J. de la, Carbonell I. and Lopez A. Design Heuristics for Innovative Packaging Ideation. In Proceeding of the $22^{\text {nd }}$ IAPRI World Packaging Conference, Monterrey, Mexico, June 2020, pp. 138-149.

[24] Butlewski M., Tytyk E., Wróbel K., and Miedziarek S. Heuristics in Ergonomic Design of Portable Control Devices for the Elderly. In Proceedings of International Conference on Universal Access in Human-Computer Interaction, Heraklion, Crete, Greece, June 2014, 24-33.

[25] Jin X. and Dong H. New Design Heuristics in the Digital Era. In Proceedings of the Design Society: DESIGN Conference, Cavtat, Croatia, May 2020, pp.607-616.

[26] Das. S and Das A. K. Development of Design Heuristics for Furniture Design. In Proceedings of ICoRD'21, Vol 3: Design for Tomorrow, Mumbai, India, Jan 2021, pp.161-173.

[27] Yilmaz S., Seifert C., Daly S.R., and Gonzalez R. Design Heuristics in Innovative Products. Journal of Mechanical Design, 2016, 138(7):071102.

[28] Hernandez N. V., Shah J. J. and Smith S. M. Understanding design ideation mechanisms through multilevel aligned empirical studies. Design Studies, 2010, 31(4), 382-410. 